\title{
Orthopaedic Biomechanics: A Practical Approach to Combining Mechanical Testing and Finite Element Analysis
}

\author{
Rad Zdero, Ph.D.1,2,3 and Habiba Bougherara, Ph.D. ${ }^{2}$ \\ ${ }_{1}^{1}$ Martin Orthopaedic Biomechanics Lab, St. Michael's Hospital, Toronto, Canada \\ ${ }^{2}$ Dept. of Mechanical and Industrial Engineering, Ryerson University, Toronto, Canada \\ ${ }^{3}$ Corresponding Author: zderor@smh.ca
}

\section{Introduction}

Clinicians and engineers have long been interested in assessing the mechanical properties of human whole bones and implant devices to address a vast array of orthopaedic pathological conditions and traumatic injury patterns. To this end, experimental methods and computational techniques have been employed over the years, separately and in combination.

Mechanical in vitro tests on human cadaveric longbones and/or longbone-implant constructs have been done for over a century (Roesler, 1987) (Fig.1). Physiologic loading is a complex interplay of anatomical geometry, material properties, muscle activity, and surrounding soft tissue. As such, experimentalists simplify matters by doing isolated axial compression, lateral bending, torsion, 3-point bending, and 4-point bending tests (Dennis et al., 2001; Fulkerson et al., 2006; Martens et al., 1980, 1986; McConnell et al., 2008; Papini et al., 2007). Although quasi-static load regimes are easier to implement practically, impact and cyclic loads simulate more realistic activities of daily living and injury mechanisms (Fulkerson et al., 2006; Mather, 1968). Pre-clinical experiments have assessed extramedullary and intramedullary fracture fixation constructs, joint arthroplasties, and longbone mechanical properties (Dennis et al., 2001; Fulkerson et al., 2006; McConnell et al., 2008; Papini et al., 2007). More complex in vivo and in situ biomechanical trials have used instrumented devices implanted into human subjects, i.e. telemetry (Bergmann et al., 1993; Schneider et al., 2001). Because of the challenges in using cadaveric bone and living subjects, synthetic bone analogs have become an attractive option. Major advantages include no special storage requirements, low cost, commercial availability, no degeneration over time, standardized geometry, and predetermined material properties (Papini et al., 2007). These surrogates have been validated against human bones with good results for axial, torsional, and 4-point bending stiffness, as well as for cortical and cancellous screw pullout strength (Cristofolini and Viceconti, 2000; Cristofolini et al., 1996; Heiner and Brown, 2001; Papini et al., 2007; Zdero et al., 2008b, 2009a). 


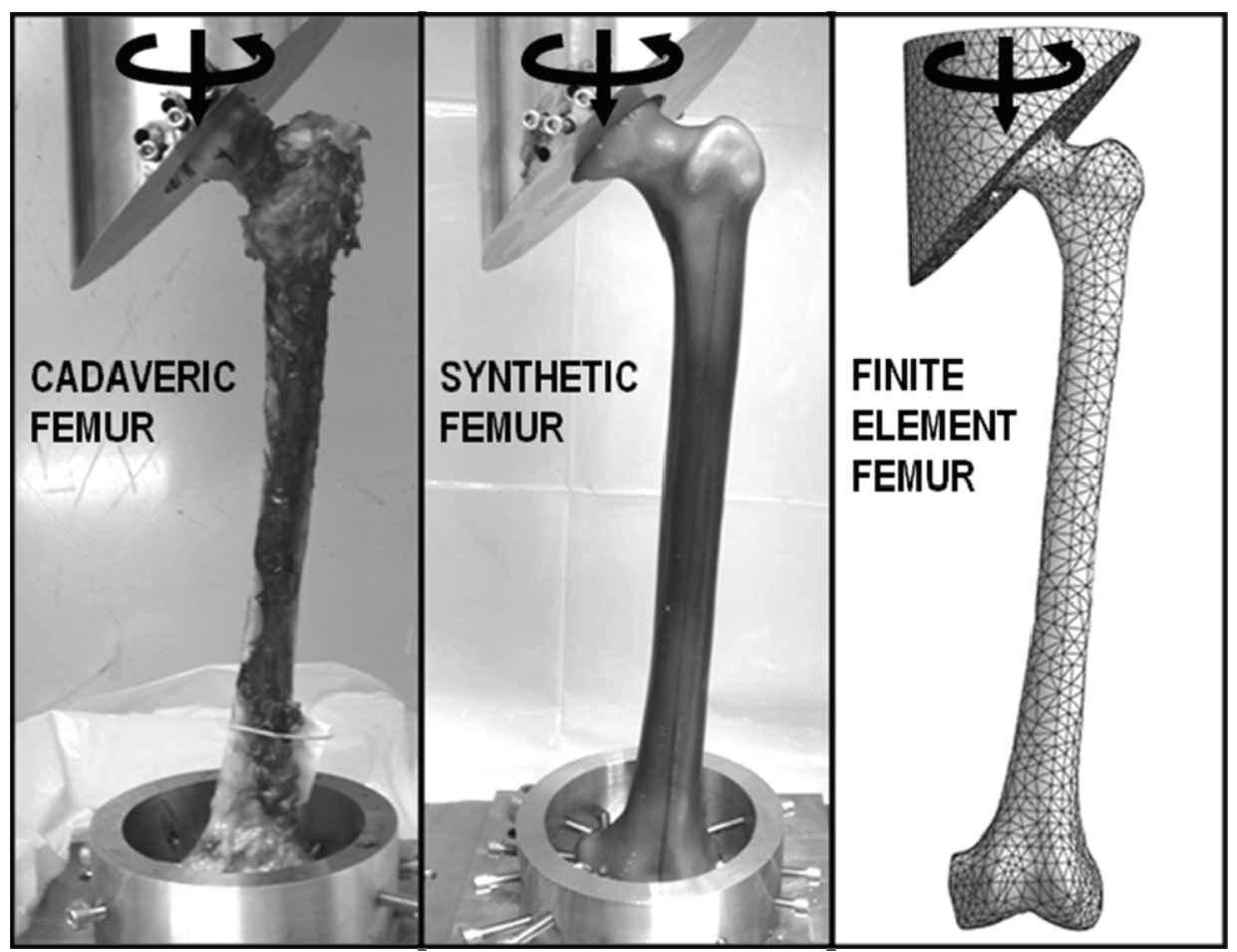

Fig. 1. The assessment of longbone mechanical properties. Experiments on a human cadaveric and a synthetic femur are simulated by a three-dimensional finite element (FE) femur model. Arrows indicate the application of axial compression and torsion.

Synthetic bones have been increasingly used to evaluate the mechanical stability of fracture fixation constructs and joint arthroplasties, as well as being characterized themselves under different loading conditions (Bougherara et al., 2009; Chong et al., 2007; Dennis et al., 2000; Dunlap et al., 2008; Lescheid et al., 2010; Papini et al., 2007; Talbot et al., 2008a, 2008b; Zdero et al., 2008a, 2010a, 2010b).

However, their exact bone quality (i.e. normal, osteopenic, or osteoporotic) has not been conclusively established, and the failure mechanisms of synthetic bone-implant interfaces have not yet been shown to be equivalent to constructs using human host bone. Future advances, therefore, will likely involve characterization and refinement of synthetic bone properties, development of a global open access database of human and synthetic bone material properties and geometries, improvement of experimental instruments and techniques, and implementation of combined loading regimes more representative of actual physiological conditions.

Finite element analysis (FEA) of bone has been done for several decades (Fig.1). The first model of human longbone in the early 1970's assumed two-dimensional geometries and used homogeneous, isotropic, elastic properties (Brekelmans et al., 1972). 


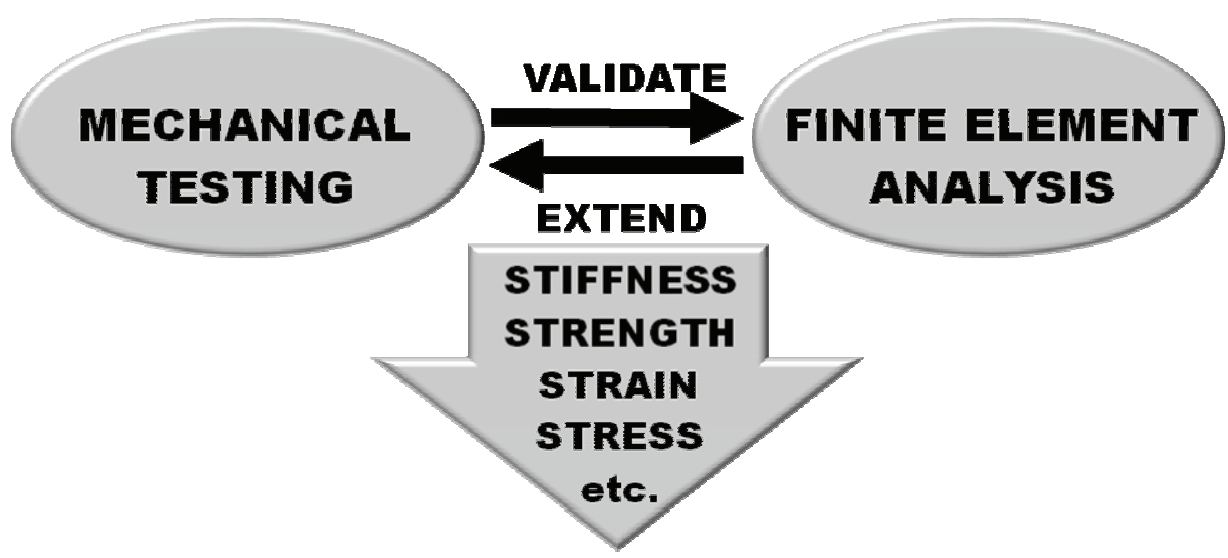

Fig.2. Orthopaedic biomechanics research diagram. The combination of mechanical testing and FEA produces outcome measures of stiffness, strength, strain, and stress.

Later models in the 1970's and early 1980's were three-dimensional, but they often used simplified tube geometries that did not necessarily mimic realistic anatomical structures or complex clinical problems (Cheal et al., 1983, 1984, 1985; Huiskes, 1982; Huiskes and Chao, 1983). Advances in computer hardware, computed tomography (CT), and computer aided design (CAD) now permit the development of more representative geometries and material properties (Bougherara et al., 2009; Cheung et al., 2004; Maldonado et al., 2003; Papini et al., 2007; Sakai et al., 2010; Taylor et al., 1996; Wang et al., 1998; van Rietbergen et al., 1995).

Finite element (FE) modeling and analysis has also been performed on a variety of cobalt chrome, titanium alloy, and polymer-based implant devices, such as longbone fracture fixation plates (Cheal et al., 1983, 1984, 1985; Oh et al., 2010), longbone fracture fixation nails (Bougherara et al., 2009, 2010a; Cheung et al., 2004), knee arthroplasty (Bougherara et al., 2010b), hip arthroplasty (Bougherara and Bureau, 2008; Davis et al., 2009; Huiskes and Stolk, 2005), elbow arthroplasty (Lewis et al., 1996), shoulder arthroplasty (Buchler and Farron, 2004; Orr and Carter, 1985), and so forth. FE models typically treat bone as a continuum, rather than focusing on its microstructural details. This approach is adequate for implant design when relative, rather than absolute, results are used to compare the performance of several devices. However, clinical conditions must be adequately replicated if the absolute quantitative performance of an implant is to be predicted. Many major challenges posed by geometry, material properties, and loading conditions for FE modeling and analysis have been identified and/or addressed in the last several decades. Future advances, therefore, will likely focus on the use of high-resolution CT scans of human bone anatomy, the employment of non-linear material properties for human tissue, the simulation of dynamic physiological loading conditions, the development of a global open access internet database of CAD models and material properties, and the importance of proper verification, validation, and sensitivity analysis (Anderson et al., 2007; Panagiotopoulou, 2009).

Although many researchers continue to legitimately carry out experimentation and FEA separately from one another, the combination of the two has advantages (Fig.2.). Experimentation, on the one hand, is able to validate to what degree an FE model can 
successfully replicate more real-world conditions, albeit those of a laboratory setting. FEA, on the other hand, is able to mimic loading conditions and extend data analysis far beyond what might be feasible to perform in a laboratory setting. Two caveats must be kept in mind, however. Firstly, experimental setups should attempt to simulate real-world physiological conditions as much as possible, although their inevitable limitations should be clearly recognized. Secondly, proper verification, validation, and sensitivity analysis of FE models should be performed to ensure that models are working properly. Studies in the biomechanics literature provide tangible examples of how mechanical testing and FEA, given their own drawbacks, can work synergistically to evaluate fracture fixation, joint arthroplasty, and the general mechanical behavior of intact limbs and joints during a variety of activities (Bougherara et al., 2009, 2010a, 2010b; Cheung et al., 2004; Iwamoto et al., 2000; Le Huec et al., 2010; Papini et al., 2007; Zdero et al., 2008b, 2010a). Most of these reports, however, assume that the reader is a somewhat informed and/or experienced experimentalist and FE analyst. As such, many details regarding technique that may be obvious to the author, but not necessarily to the reader, go unreported. Moreover, to the authors' knowledge, there is little in the way of explicit instructional material that addresses the issue of how mechanical testing and FEA can work together.

The aim of this article, therefore, will be to present some practical tools to students, engineers, and clinicians for combining mechanical experiments and FEA to successfully carry out orthopaedic biomechanics research. Specifically, an overview will be given of the purpose, principles, outcome measures, resources required, data assessment, and the various tips, tricks, and troubles when performing mechanical testing and FEA as independent research modalities. This will be followed by a practical case study of a realworld orthopaedic biomechanics problem in which mechanical assessment and computational analysis will be used in combination to generate results.

\section{Mechanical Testing}

\subsection{Purpose}

The purpose of in vitro biomechanics testing is to generate valuable pre-clinical information to the researcher and clinician (Fig.3). It allows for the mechanical characterization of intact human joints, longbones, and soft tissues. It assesses the performance of joint prostheses and bone-implant fracture fixation constructs. It allows engineers and surgeons to make improvements to the design of a potentially new implant or surgical technique under controlled laboratory conditions. It helps investigators to decide whether or not to expend the time, energy, resources, and finances on subsequent clinical studies in live animal or human subjects. It prevents the premature introduction of new orthopaedic devices into the market and their implantation into patient populations. In this regard, there has been a recent recognition of the need for an evidence-based approach in bringing new orthopaedic devices to market, which follows a sequential hierarchy of evaluation approaches, starting with basic biomechanical testing (Schemitsch et al., 2010).

\subsection{Principles}

Several principles should be considered when designing and performing biomechanical tests with respect to specimen factors, testing conditions, and measurement instruments (Fig.3) (Baird, 1962; Holman, 2000). 


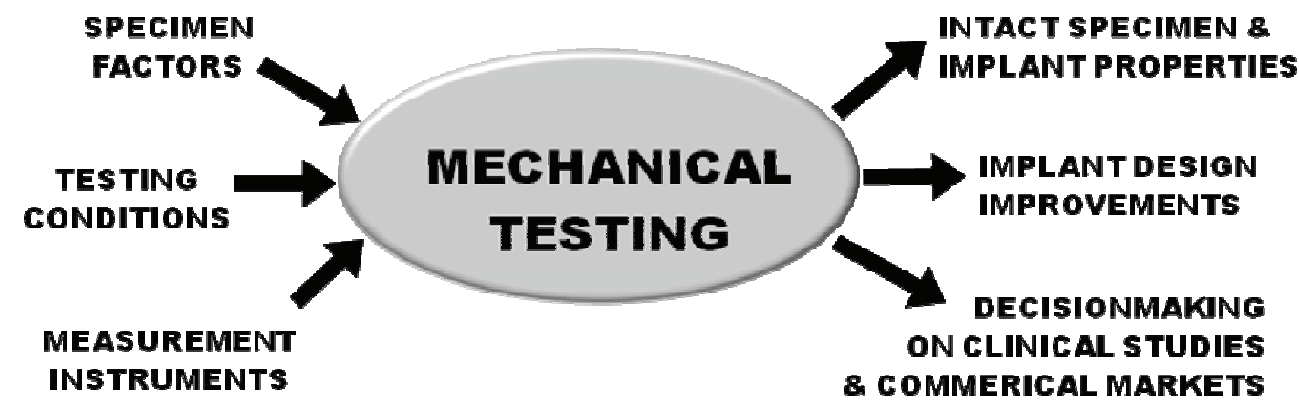

Fig. 3. Overview of mechanical testing shows required inputs and resulting outputs.

Specimen material properties of cadaveric human, cadaveric animal, or synthetic specimens should be similar to in vivo tissue whenever possible. Specimen baseline properties should be established for control specimens or control groups. The number of specimens per test group when statistical comparisons will be made should be sufficient to detect all differences actually present, i.e. to avoid type II error. Test conditions, such as loading modes, loading levels, and specimen fixation devices, should approximate in vivo conditions whenever possible.

Test conditions should be identical from specimen to specimen, unless otherwise required. Test conditions should have precedent in the scientific literature and/or abide by established technical standards, like the ISO (International Standards Organization), ANSI (American National Standards Institute), and ASTMI (American Society for Testing and Materials International), as well as conforming to the ethical standards established by institutional and organizational committees if human or animal specimens are used. Measurement instruments should interfere only minimally with the test setup and specimen. Measurement instruments should be calibrated for accuracy and precision and their range and resolution identified. Measurement instruments and methods should be performed and reported so they are reproducible by others investigators.

\subsection{Outcome Measures}

Some questions should be asked before choosing which mechanical outcome measure(s) will be assessed experimentally. Is it practically feasible to measure? Is it clinically relevant? Is it reproducible by other investigators? Is it sufficient alone or must it be supplemented by other parameters? Although there are a variety of measurements made in biomechanics studies, several are of particular importance. Stiffness is the force required to generate a unit of displacement prior to any permanent damage to a specimen, i.e. the slope of the linear portion of the force-vs-displacement curve. Strength from a mechanical standpoint is the maximum force needed to cause structural failure of a specimen, i.e. the absolute peak force of the force-vs-displacement curve. Alternately, strength from a clinical standpoint is the force needed to reach a physiologically relevant maximum displacement, i.e. the force corresponding to the pre-determined clinical displacement criterion. Strain is the relative deformation per unit length at a location on the test specimen. Stress is the amount of relative force per unit area at a location on the test specimen. 


\subsection{Equipment Required}

Several pieces of equipment are vitally important for the biomechanical experimentalist. A mechanical tester such as Instron (Instron Corp., Norwood, MA, USA) or MTS (MTS Systems Corp., Eden Prairie, MN, USA) should be obtained with both axial and torsional load application capabilities. Uniaxial and rosette strain gages accompanied by a dedicated data acquisition system measure specimen surface strains that can be converted to stress values, e.g. strains at several points along the lateral surface of a tibia undergoing axial compression. Pressure sensitive layers like Fuji film (Fuji Prescale USA, Madison, NJ, USA) and K-scan (Tekscan Inc., South Boston, MA, USA), respectively, measure the static and dynamic contact stresses and areas at interfaces, e.g. an intact knee or a total knee prosthesis. linear velocity differential transformers such as the LVDT (Macro Sensors, Pennsauken, NJ, USA) and angular displacement transducers like the ADT (Trans-Tek, Ellington, CT, USA) measure the relative motion between any two bodies, e.g. the relative movement of adjoining bone fragments at a fracture site.

\subsection{Data Assessment}

Data analysis will be approached depending on the type of study performed. Statistical studies are used to determine definitively whether or not outcome measures are different between test groups representing pathological conditions, injury patterns, or normals. A power analysis should be done (preferably before the study) to ensure an adequate number of specimens per group to permit detection of all the statistical differences that actually exist, i.e. avoid type II error. Non-statistical studies are usually used to detect patterns or relative changes of an outcome measure on the same specimen under different conditions. However, when comparing two or more specimens, each of which represent a pathology, injury, or normal subject, a definitive statement about statistical differences cannot be made. Data correlation using the Pearson coefficient of determination $\left(\mathrm{R}^{2}\right)$ is a common approach. As a general guideline, there is low correlation if $0<\mathrm{R}^{2}<0.4$, there is moderate correlation if $0.4<\mathrm{R}^{2}<0.8$, and there is high correlation if $0.8<\mathrm{R}^{2}<1$. It can be employed to determine if two outcome measures are strongly interdependent, e.g. bone density and ultimate failure stress. It is also used to describe the linearity of the data scatter during a measurement process, e.g. if specimens were kept within the linear elastic region during stiffness tests based on the force-vs-displacement curve.

Data display can be done using one of two formats. Absolute values allow for comparison of results to known biomechanical threshold values, e.g. material yield stress, or clinical threshold values, e.g. prosthesis failure displacement. The researcher, however, can still highlight certain findings by reporting the percentage change seen for a particularly important outcome measure. Normalized values present a direct comparison of results to a control group, e.g. normal subjects, or a control specimen, e.g. intact longbone. In this case, the researcher should still report the absolute values of the control group to which all other data have been normalized. Whether data are given as absolute or normalized values, it is important to present enough data to allow for adequate interstudy comparison.

Data interpretation of results from in vitro biomechanics studies cannot provide or predict the absolute values of in vivo clinical conditions. Rather, mechanical testing gives results that allow for an understanding of the relative performance to one another of the test groups or individual specimens assessed, e.g. the failure strength of implant A versus the failure 
strength of implant B. Even so, it is likely that the relative performance can be generalized to actual physiological conditions in vivo.

\subsection{Tips, Tricks, and Troubles}

Long investigation times can change the mechanical properties of cadaveric bone and boneimplant constructs if the study lasts several weeks or months. For example, a 30\% decrease in axial stiffness of femur-implant constructs at an applied load of $500 \mathrm{~N}$ can occur over several months during the experimentation period (McConnell et al., 2008). This may happen if the bones are fresh, stored in a freezer, and repeatedly refrozen and re-thawed because all experiments could not feasibly be performed within a shorter period of time. Additionally, implant "migration and settling" within the host bone may also be a factor in this regard as cumulative damage is incurred over time from test-to-test.

Embalming of cadaveric bones and bone-implant constructs could alter the mechanical properties of bone. Several prior investigations, however, have demonstrated that embalming does not significantly affect bone's mechanical properties (McElhaney et al., 1964; Wainer et al., 1990). Bone mineral density levels measured using dual x-ray absorptiometry (DEXA) reach a steady-state value and remain unchanged, but only if the specimens have been embalmed for several months (Lochmuller et al., 2001). The correlation between bone mass and strength appears to be unaffected by embalming (Edmondston et al., 1994). Given the fact that embalmed specimens, unlike fresh frozen specimens, do not require any special storage requirements beyond the bones being placed in a plastic bag at room temperature, they may be a feasible choice for biomechanical experimentation.

Soft-tissue stripping of muscles, tendons, ligaments, and other tissues allows investigators to isolate cadaveric bone for easier preparation and mechanical testing. This greatly simplifies experiments. However, this ignores the important immediate and longterm role of surrounding tissues in generating forces and moments that influence the stability of joints and bone-implant constructs, as well as bone fracture healing and union. For instance, during the stance phase of normal walking at a speed of $1.2 \mathrm{~m} / \mathrm{sec}$, the three tibio-femoral joint force peaks are due primarily to the activity of the hamstrings ( 3.3 times body weight), the quadriceps ( 2 times body weight), and the gastrocnemius ( 2.5 times body weight) (Schipplein and Andriacchi, 1991). Even so, numerous prior investigators have used cadaveric bone stripped of all tissue to successfully assess the relative levels of mechanical stiffness and strength achieved for intact and/or instrumented femurs (Davis et al., 2008; Dennis et al., 2001; Fulkerson et al., 2006; McConnell et al., 2008; Papini et al., 2007).

Loading modes most commonly utilized in testing cadaveric and synthetic longbones and longbone-implant constructs are axial compression, lateral bending, 3- or 4-point bending, and torsion (Bougherara et al., 2009; Cristofolini and Viceconti, 2000; Cristofolini et al., 1996; Davis et al., 2008, 2009; Dennis et al., 2000, 2001; Fulkerson et al., 2006; Martens et al., 1980, 1986; McConnell et al., 2008; Papini et al., 2007; Talbot et al., 2008a, 2008b; Zdero et al., 2008a, 2010a, 2010b). These are meant to simulate the various loading orientations of longbone that might be encountered during common activities of daily living, such as walking, running, jumping, stair climbing/descending, sitting/rising from a chair, etc. Needless to say, there is a large variety of possible conditions that longbones might experience during injuries and accidents which may be difficult to predict and simulate experimentally. As such, a large proportion of experimental biomechanics research attempts 
to mimic common activities such as level walking, in which the femur is primarily in a state of axial compression (Duda et al., 1998; Taylor et al., 1996).

Quasi-static tests are used by many investigators to determine the stiffness and strength of longbone or longbone-implant constructs (Bougherara et al., 2009; Cristofolini and Viceconti, 2000; Cristofolini et al., 1996; Davis et al., 2008, 2009; Dennis et al., 2000; Martens et al., 1980, 1986; McConnell et al., 2008; Papini et al., 2007; Talbot et al., 2008a, 2008b; Zdero et al., 2008a, 2010a, 2010b). However, the influence of cyclic fatigue should also ideally be considered when appropriate, since it can cause microdamage and micromovement at the various interfaces created by contact between cement, screws, wires, plates, nails, and arthroplasties with the host bone, thereby potentially leading to decreased longboneimplant stiffness and failure strength (Dennis et al., 2001; Fulkerson et al., 2006; Talbot et al., 2008a). Additionally, some investigators have given attention to simulating impact loading conditions that might occur during falls, which may be particularly relevant for the elderly, or motor vehicle accidents, which may be especially salient for young people with good bone stock (Alho, 1996; Elstrom et al., 2006; Mather, 1968).

Strain gage placement will affect the reliability and reproducibility of results. Gages should ideally be positioned on flat and smooth surfaces, so they will be able to optimally detect the planar strains at that location. Conversely, curved and textured surfaces under load could produce strains over an arc length that would result in an unstable strain gage signal. Moreover, gages should be positioned away from structural discontinuities where there is a steep strain gradient, such as fracture sites and rigid fixation systems, whose proximity could render the gage readings meaningless.

Interspecimen variability between cadaveric tissue with respect to material properties and geometry is a drawback. For instance, axial and torsional stiffnesses for intact human femurs can vary by 3.3 and 3.2 times, respectively (Papini et al., 2007), while for intact human scapholunate ligaments variation can be 28.7 and 9.7 times, respectively (Zdero et al., $2009 \mathrm{~b})$. This can pose a challenge in creating a test apparatus or longbone-implant construct with boundary conditions that are able to apply or absorb forces in an identical manner for each specimen. Specimen-to-specimen variability can also lead to a large variation in measured results which are sometimes awkward to accommodate even by normalization relative to control group results. This makes it difficult to draw useful conclusions from a given study. Moreover, researchers may also be faced with the challenge of appropriately comparing their results with previously published investigations.

Synthetic longbones are being increasingly used and have afforded researchers a number of advantages over cadaveric specimens (Cristofolini and Viceconti, 2000; Cristofolini et al., 1996). Synthetic longbones have a standardized geometry that is 20-200 times more uniform than cadaveric bones. There are no special storage requirements. There is no degeneration over time that affects the mechanical properties. Toxicity and financial cost are low. They are commercially available. Moreover, these bones have been shown to replicate human bone axial stiffness, torsional stiffness, 4-point bending stiffness, cortical screw pullout strength, and cancellous screw pullout strength (Cheung et al., 2004; Cristofolini and Viceconti, 2000; Cristofolini et al., 1996; Heiner and Brown, 2001; Papini et al., 2007; Zdero et al., 2008b, 2009a). As such, a number of experimental investigations using these analogs have been reported in the literature to evaluate intact and instrumented longbones (Bougherara et al., 2009; Dennis et al., 2000; Lescheid et al., 2010; Talbot et al., 2008a, 2008b; Zdero et al., 2008a, 2010a, 2010b). However, it has not been shown conclusively that the failure mechanisms of 
implants in synthetic host bone are equivalent to those found in cadaveric host bone, therefore, failure strength measurements must be considered cautiously.

Clinical fracture patterns are often complex, resulting in multiple fragments, bone loss, and jagged fracture patterns (OTA, 1996). The interdigitating nature of complex fracture patterns may provide enhanced stability, since interfacial slip at the fracture site between adjoining segments of bone may be reduced. In contrast, experimentalists often simulate simpler injury patterns with smooth bone cuts because they are more easily created in the laboratory setting, thereby permitting duplication of multiple test specimens (Dennis et al., 2000, 2001; Fulkerson et al., 2006; McConnell et al., 2008; Talbot et al., 2008a, 2008b; Zdero et al., 2008a). As such, stiffness and strength may actually be higher clinically than measured experimentally, which may provide a conservative lower estimate.

Biological factors cannot be taken into account by in vitro tests. Biological differences between people will contribute to the degree of fracture healing, limb and joint function, and stability after surgical repair of fractures and implantation of joint prostheses (Claes and Ito, 2005; Huiskes and Van Rietbergen, 2005; Perren, 1975). Biological elements include variations in intrinsic healing capacity of various segments of the longbone, bone quality as influenced by osteoporosis and osteopenia, the organization and structure of osteons, and longbone nutritional needs. This interplay between mechanics and biology substantially influences the stress levels experienced by longbone and, thus, the quality of fracture healing between adjoining bone fragments and bony ongrowth around implant devices.

\section{Finite Element Analysis}

\subsection{Purpose}

The purpose of Finite Element Analysis (FEA) in the field of orthopaedic biomechanics is to predict the mechanical behavior of bones, develop and improve the design of implants, and eliminate and/or minimize the time and cost involved for in vivo and in vitro experimentation (Fig.4). FE modeling is also used to simulate the bone remodeling and healing phenomena of conventional and biomimetic devices, such as hip replacements (Bougherara et al., 2010c; Huiskes et al., 1987; Hernandez et al., 2000). More recently, computational modeling combined with biochemistry, bone biology, and thermodynamics was used to develop new therapeutic strategies associated with bone loss and other bone related diseases (Bougherara et al., 2010d; Huiskes et al., 2000; Rouhi et al., 2007).

\subsection{Principles}

The development of FE models in orthopaedic biomechanics starts with the acquisition of data using medical imaging techniques, such us computed tomography (CT) scans and magnetic resonance imaging (MRI) (Bougherara et al., 2007). These scans should be of sufficient resolution to allow for accurate replication of the geometries of interest. These data are then converted into realistic three-dimensional geometries of the bone tissue of interest using medical imaging software. The software should have a known minimal or zero error in the relative positioning of the image slices that make up these threedimensional reconstructions. To generate the geometry of prostheses that will be inserted into joints or bones, computer aided design (CAD) software can be employed. The exact positioning of the implant into the bone tissue in the FE model should be verified by $x$-rays to accurately replicate laboratory experiments or clinical scenarios. 


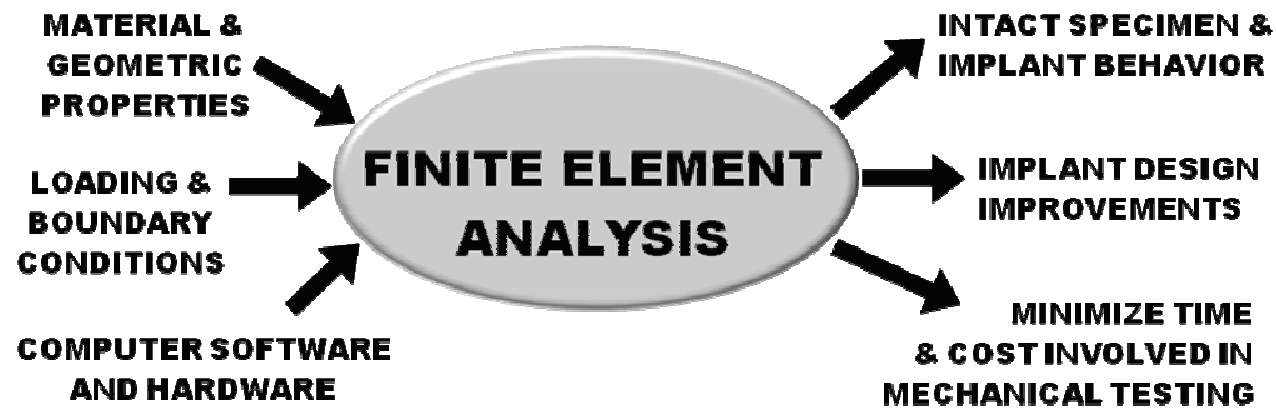

Fig. 4. Overview of FEA shows required inputs and resulting outputs.

At this stage, the assembled geometry is ready to be exported into a softawre simulation package for analysis. Material properties should be assigned to the bones and implants and physiological load conditions should be applied that are reflective of real-world conditions. FEA should then be performed to obtain a variety of outcome measures, such as stiffness, strength, strain, and/or stress. It should be recognized that the accuracy of the FEA results will rely on the assumptions made to build the FE model. Given the fact that it is very difficult to develop and analyze any model without any assumptions, therefore, it is important to understand to which extent such assumptions may affect the analysis of the results.

Typical assumptions may concern input data, such as material and geometric properties, loading and boundary conditions, subsequent analysis, and the interpretation of results. Each of these has its own set of limitations which will affect the final calculated results.

\subsection{Outcome Measures}

Typical outcome parameters relevant to clinicians and engineers include bone quality or stiffness, strength, strain, and stress. The combination of FE approaches with numerical algorithms offers potential measurements such as bone density and damage accumulation. In addition, modern FE software packages can offer advanced tools, such as shape and topology optimizations. Any successful FEA must be reproduced by experimental tests. The adequacy of the outcome parameters must be verified by comparison with previous studies and/or clinical observations. Experimentally, strain gages provide a fundamental comparison with FE predictions of average deformations at particular locations on the bone implant surfaces. Thus, FEA is advantageous since it provides a detailed map of strains and stresses of the entire structure, unlike strain gages which provide measurements only at single discrete locations.

\subsection{Software and Hardware Required}

Three types of software are needed to complete FEA of any structure. Firstly, a computer aided design (CAD) package or a three-dimensional (3D) scanner are needed to create the solid model of the bone or implant. In terms of accuracy, 3D scanners (NextEngine, Inc., Santa Monica, CA, USA) are better for generating CAD models than conventional approaches, which require physical measurements of an object. The 3D scanners 
systematically and automatically create highly detailed digital models. Secondy, an FE program package is needed for analysis. Packages such as ANSYS, Inc., ABAQUS, and Altair Engineering combine CAD and FE programs into a single software package, thereby creating a user friendly environment. Thirdly, to generate 3D models of complex geometries, such as bone tissues where density measurements are crucial, medical imaging software (Mimics ${ }^{\circledR}$, Materialise Group, Leuven, Belgium) processes CT images and transforms them into 3D models. SolidWorks can be used to develop geometries of prosthetic implants. The bone and implant can then be assembled to replicate the experimental setup and exported for analysis to ANSYS Worbench (ANSYS Inc., Canonsburg, PA, USA). Since FE models often need considerable computational time, it is recommended to use a computer known for rapid numerical data processing in order to reduce central processing unit (CPU) time and storage costs.

\subsection{Data Assessment}

Data analysis in FEA can be either structural or statistical in nature. Structural analysis allows the quantification of normal and shear stresses, strains, and strain energy densities, as well as investigating different failure modes of the bone and/or implant under physiological load conditions. Statistical analysis enables the prediction of the uncertainty in the modeling variables on the biomechanical behavior of the bone implant system. For example, stochastic approaches such as the Monte Carlo method can be used to evaluate the probability of bone fracture under static loading conditions.

Data correlation of FEA data with experimental data can be done using the Pearson coefficient of determination $\left(\mathrm{R}^{2}\right)$. This coefficient is an indicator of the validity of the FE model by determining the level of agreement between FE and experimental results.

Data display of FEA results allows the analyst to observe minimum and maximum stress values, either in nodes or elements, which can be used to measure the risk of bone failure. Conversely, Von Mises stresses (i.e. averaged values of the principal stresses) are used to quantify the load transfer after prosthetic implantation. Other quantities, such as strain energy density values, are used to investigate stress shielding and bone loss. Thus, depending on the parameter investigated, different outcome measures can be displayed.

Data interpretation of FEA results focuses on the assessment of the mechanical performance of implants and/or bones to predict their mechanisms of failure. This can lead to the optimization of prosthetic implants and improved surgical procedures. However, FEA results should be interpreted with caution when used as a basis for clinical treatment.

\subsection{Tips, Tricks, and Troubles}

Material properties are chosen for bones which sometimes may not be reflective of actual clinical conditions. Often, assumptions of linearity and homogeneity of properties are made to simplify modeling and analysis by simulating commercially available synthetic bones. Although this may initially appear problematic, these analog bones, for instance, can replicate the non-homogeneity of human bone. However, synthetic bones are unable to mimic human bone anisotropy, which affects the bulk mechanical behavior of bones. Nevertheless, a comparison of FE analysis, synthetic femurs, and human cadaveric femurs previously performed suggests that linearity is a fairly good approximation of the behavior of femurs as a whole (Bougherara et al., 2009, 2010a, 2010b; Papini et al., 2007) 
Implant positioning of prostheses into host bone can be difficult to accomplish using FE modeling. Malpositioning and the mode of fixation of the implant may affect the load sharing between the implant and host bone tissue (Lotke and Ecker, 1997; Shimmin et al., 2010). To overcome this problem, $x$-rays of the bone-implant system or computer-aided periprosthetic planning should be used to assist with implant position.

Boundary conditions at the interfacial contact regions may affect the mechanism of load sharing between implants and host bone. In order to achieve perfect osseointegration, i.e. bony ongrowth around the implant, bonded contact at interfaces is usually assumed in FE models. In reality, such a case is unlikely to occur. The incorporation of frictional contact in FE models is important, since it affects the longterm stability of orthopaedic implants (Dammak et al., 1997; Forcione and Shirazi, 1990).

Loading levels considered in most FE models are sometimes much lower than real physiological loads. Most frequently, only static joint forces acting on the bone tissue are considered, while the remaining forces due to the activity of muscles, tendons, ligaments, and other surrounding soft tissues are neglected. This simplifies FEA greatly. However, some researchers have shown that the stress distribution in cancellous bone, since it is prone to stress shielding, is dominated by the vertical component of the joint reaction force (Taylor et al., 1995). In fact, the magnitude of stress shielding and bone resorption may be underestimated by FE models (Simões and Marques, 2005).

Osteolysis or bone resorption, which is due to alterations in the stress distribution of the bone and implant, are often not replicated by FE models. Studies are restricted to analyzing the stress-strain pattern in the bone-implant system. While models of bone adaptation to loading environments exist in published literature (Bougherara et al., 2010c; Huiskes et al., 1987; Taylor et al., 1999; Weinans at al., 1993), no doubt a favorable prediction of bone adaptation will further help assess the potential of implants used in orthopaedics.

Three-dimensional reconstruction of muscles and tendons remains a significant challenge in biomechanics, despite the considerable potential of FEA. It is very difficult to identify the exact locations and intersections of the muscles, as well as their thickness, even from high resolution MRI images (Schutte et al., 2006).

Geometric defects resulting from the reconstruction of bone tissue using CT scans and the subsequent segmentation phase can be optimized using special software, such as Geomatic Studio (Geomatic, Inc., Research Triangle Park, NC, USA), for healing and optimizing complex surfaces. Further topological optimization tools are also available in AnsysWorkbench Suite.

Mesh type, size, and relevance are crucial for the success of FEA simulations. The choice of the mesh type depends on two factors, namely, ease of generation and high quality or accuracy. Hexahedral meshes are quite difficult to generate (Schonning et al., 2009), but offer more accuracy than tetrahedral meshes, particularly for biomechanical applications involving contact analysis. However, tetrahedral meshes can be used if validated with experimental results (Papini et al., 2007). Furthermore, it is important to optimize the mesh sensitivity using mesh refinement tools, in order to obtain a high quality mesh, keeping in mind the computation cost, such as CPU time, data storage, software required, hardware required, human cost, etc. 


\section{Case Study: The T2 Intramedullary Nail for Fixing Femoral Shaft Fractures}

\subsection{Background}

Intramedullary femoral nails are the most common method of fixing fractures of the femoral diaphysis (Pankovich and Davenport, 2006). The T2 Femoral Nailing System (Stryker, Mahwah, NJ, USA) provides surgeons with a multi-functional nail that can be oriented in antegrade (inserted into the proximal femur end) or retrograde (inserted into the distal femur end) and can be fixed to the femur with standard or advanced locking. Advanced (or dynamic) locking uses oblong holes to permit up to $10 \mathrm{~mm}$ of motion in either the distal or proximal end of the femur. Advanced locking allows for load transfer through the fractured ends of the femur and has both locked and unlocked modes by which the movement of the nail within the femur is restrained. Presently, results are given of a retrograde nail (RA-on) and an antegrade nail (AA-on) with advanced locking activated. Outcome measures included axial stiffnesses, strain distributions along the medial surface of the femur, and three-dimensional stress maps of the femur-nail construct. This case study is a brief summary of a more comprehensive prior examination by the current authors of the T2 nailing system implanted into synthetic femurs (Bougherara et al., 2009).

\subsection{Mechanical Testing}

Two large left Third Generation Composite Femurs (Model 3306, Pacific Research Labs, Vashon, WA, USA) were obtained and instrumented with T2 Femoral Nailing Systems (Stryker, Mahwah, NJ, USA) (Fig.5a). Implantation was done using the manufacturer's protocol by an orthopaedic surgeon. One femur had a nail inserted retrograde with advanced locking activated (RA-on). The other femur had a nail inserted antegrade with advanced locking activated (AA-on). Femurs were not osteotomized, thereby modeling an anatomically-reduced mid-shaft fracture which has begun to heal 6 weeks after surgical repair (Schneider et al., 1990, 2001).

Femurs were instrumented with five general purpose uniaxial linear pattern strain gages (Model CEA-06-125UW-350, Vishay Measurements Group, Raleigh, NC, USA). Gages were spaced $40 \mathrm{~mm}$ apart along the medial surface, starting at $20 \mathrm{~mm}$ proximal to the lesser trochanter. Wire leads were soldered to each gage, secured to the femur using electrical tape, and attached to an 8-channel Cronos-PL data acquisition system (IMC Mess-Systeme $\mathrm{GmbH}$, Berlin, Germany). This system was attached to a laptop computer for data collection and signal analysis using FAMOS V5.0 software (IMC Mess-Systeme GmbH, Berlin, Germany).

Femurs were secured distally using nine pointed screws inserted into the cortex of the condyles through holes in a stainless steel ring-like jig. The jig was mounted rigidly onto the baseplate of the test machine. All experiments were done on a mechanical tester (MTS 793, MTS Systems Corporation, Eden Prairie, MN, USA).

A vertical compressive load to the femoral head was applied using displacement control (max displacement $=0.5 \mathrm{~mm}$, rate $=10 \mathrm{~mm} / \mathrm{min}$ ). The load applicator was a flat plate. No slippage of the femoral head at the applicator-head interface was visually observed. The slope of the load-vs-displacement curve was defined as axial stiffness. Based on stiffness, a displacement value was then calculated and used as the maximum value for a second test run to reach $580 \mathrm{~N}$, as done previously (Cheung et al., 2004). It was during this second test run that final strain gage values were recorded and averaged over a 30 second period. 


\subsection{FE Modeling and Analysis}

For the T2 nail, SolidWorks 2007 CAD software was used to create a solid model of the same nail used experimentally (Fig.5b and 5c). From a basic cross-section, the "sweep" function was used to extrude the nail geometry. Holes were cut and chamfers were added to simulate the nail. The channels running down the exterior surface of the nail were omitted, and a circular cross-section was maintained along the length of the nail. A second CAD model was created to aid in the ANSYS DesignModeler assembly prior to FEA. This "dummy" model did not have holes cut and did not have a canal running along its length.

For the synthetic femur, CT scans were performed every $0.5 \mathrm{~mm}$ along the length of the same synthetic femurs used experimentally (Fig.5b and 5c). Using MIMICS Medical Imaging Software, cross-sectional geometries of the femur were exported into SolidWorks 2007 Suite and used to fit splines representing the boundaries of the cortical and cancellous bones. The splines were imported into SolidWorks and joined together using a "loft" function, resulting in separate cancellous and cortical CAD models. The intramedullary canal was created by cutting away from the cancellous bone.

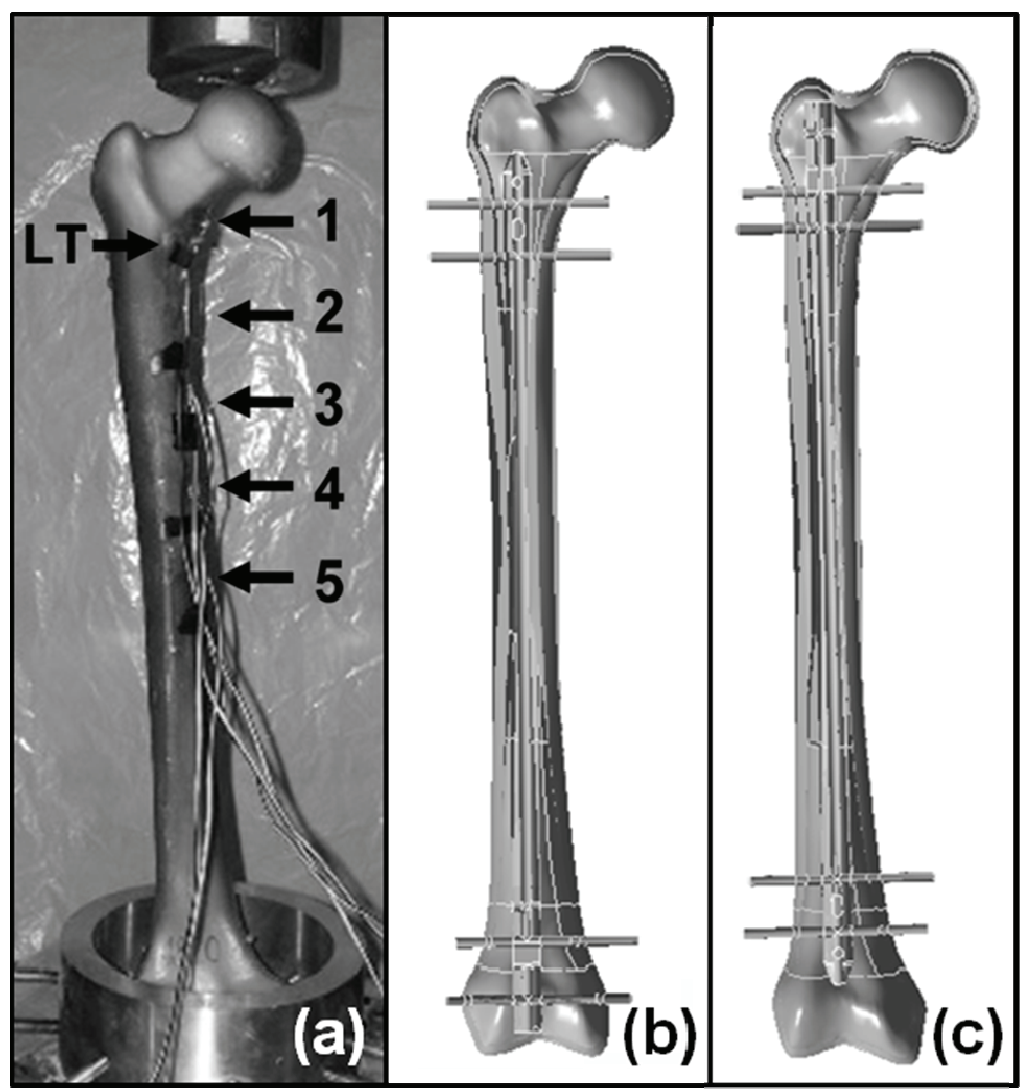

Fig. 5. T2 nail configurations. (a) Experimental setup of femur-nail instrumented with strain gages 1 to 5. (b) CAD model for RA-on nail inserted from the bottom of the femur. (c) CAD model for AA-on nail inserted from the top of the femur. LT is the lesser trochanter. 
To assemble the CAD models, the cancellous bone, cortical bone, and T2 models were imported into SolidWorks 2007. The T2 nail was positioned into the intramedullary canal while attempting to minimize intrusion into the cortical bone. The exact position of the nail was verified by $x$-rays of the experimental specimens. The use of CAD-modeled screws was avoided by simulating partially and fully threaded screws with pins $5.0 \mathrm{~mm}$ in diameter. A flat plate load applicator was added to simulate the loading on the femoral head. ANSYS DesignModeler was used to import the SolidWorks 2007 models into ANSYS. A "dummy" nail was imported and a slice operation introduced to remove any cortical and cancellous bone overlapped by the T2 nail. The actual CAD model of the T2 nail was then imported and fitted into the space left by the slice operation. Any unwanted residual elements were suppressed, and the geometry was exported for FEA to be carried out.

Regarding mesh creation, ANSYS Workbench 10.0 was used. For the RA-on nail configuration, the number of nodes and elements was 51,108 and 24,530, respectively. For the AA-on nail configuration, the number of nodes and elements was 48,520 and 23,198, respectively. Body elements used were 10-Node Quadratic Tetrahedron for the cortical bone, cancellous bone, and T2 nail and pins, whereas a 20-Node Quadratic Hexahedron was used for the flat plate load indenter. Contact elements used were Quadratic Triangular for the cortical bone, cancellous bone, and T2 nail and pins, whereas a Quadratic Quadrilateral was used for the load applicator. Mesh relevance for both configurations was $>80 \%$.

Concerning material properties, the T2 nail was set at values for titanium (E=110 GPa, $v=0.3)$. Synthetic femurs were assumed to be isotropic and linearly elastic with material properties for cortical $(\mathrm{E}=10 \mathrm{GPa}, v=0.3)$ and cancellous $(\mathrm{E}=206 \mathrm{MPa}, v=0.3)$ based on a previous study on the same bone (Cheung et al., 2004). The value for Young's Modulus of cortical bone $(\mathrm{E}=10 \mathrm{GPa})$ was an average of compressive $(7.6 \mathrm{GPa})$ and tensile $(12.4 \mathrm{GPa})$ values (Cheung et al., 2004).

FEA was done in the Simulation window of ANSYS Workbench 10.0 suite. The displacement of the distal end of the femur was restrained. This was an approximation of the nine-point jig used in experimental trials. The loading simulated that of the experimental apparatus with a flat plate load applicator applying $580 \mathrm{~N}$ at the apex of the femoral head. Contact regions between the T2 nail and synthetic femur were set to frictional (coefficient = 0.08) (Grant et al., 2007). For advanced locking activated, the pins set in dynamic positions were allowed to have frictionless contact with the nail, while maintaining bonded contact to the femur. All other pin and bone contacts were set to bonded. The contact region between the indenter and femoral head was set to bonded, assuming that there would be no slipping.

\subsection{Mechanical Testing Results}

Axial stiffness results are shown (Fig.6). The AA-on configuration was 1.7 times stiffer than the RA-on configuration. The average linearity coefficient for axial load versus axial displacement data was $\mathrm{R}^{2}>0.99$. Thus, specimens remained within the linear elastic region and incurred no permanent damage during tests. Compressive microstrains along the medial surface of the femur ranged from 294 to 968 (Fig.7). As anticipated, the highest strain values occurred for proximal Location 1 (968, RA-on) or Location 2 (820, AA-on) at the base of the femoral neck, since the bone there is composed of a soft cancellous region with only a thin cortical shell. This allows for substantial bending during axial compression. 


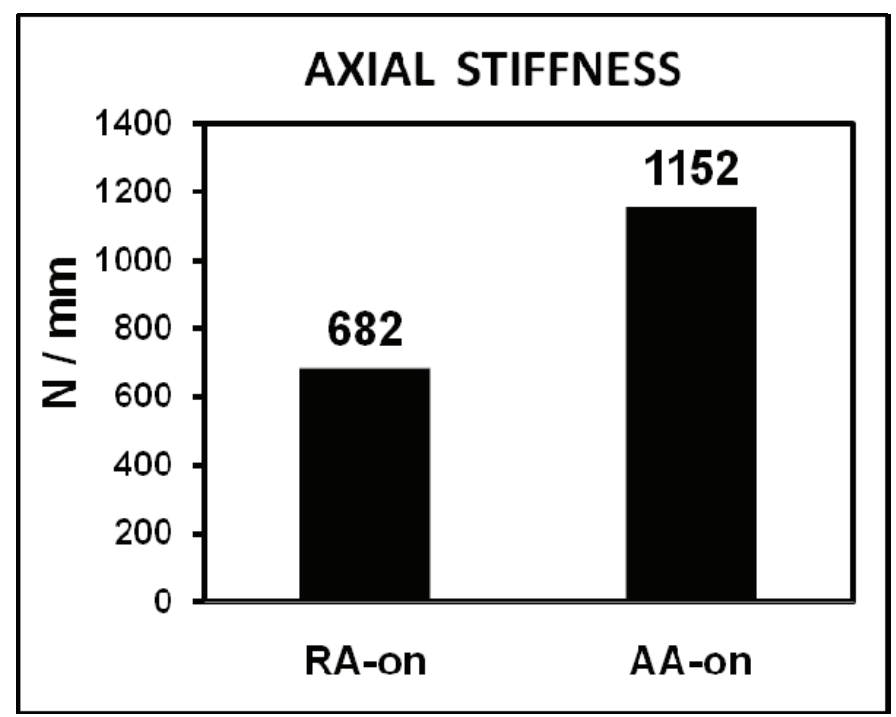

Fig. 6. Experimental stiffness results for RA-on and AA-on configurations. The AA-on femur-nail construct was 1.7 times stiffer than the RA-on femur-nail construct.

The lowest strain values occurred for distal Location 5 (294, RA-on; 302, AA-on) at about the midpoint of the femoral shaft, since the bone there is composed solely of rigid cortical material. This prevents substantial bending during axial compression. A highly linear relationship existed for strain gage values (microstrain) versus strain gage location $(\mathrm{mm})$ along the medial length of the femurs, yielding linear correlation coefficients of $R^{2}=0.88$ (RA-on) and $\mathrm{R}^{2}=0.91$ (AA-on). This illustrated the uniformity of material properties and strain along the medial surface of the femur bone.

\subsection{FEA Results}

FE strain readings were taken at the same strain gage locations as experimentally. Elastic (Von Mises) strain readings were used and represent compressive strains occurring at each location, ranging from 363 to 799 (Fig.7). A linear relationship was noted for the FE results between gage value (microstrain) and location $(\mathrm{mm})$ along the femur, yielding $\mathrm{R}^{2}=0.89$ (RA-on) and $\mathrm{R}^{2}=0.83$ (AA-on). FE strains agreed reasonably well with experimental strains, showing that the actual line of best fit $\left(\mathrm{R}^{2}=0.89\right.$, slope $\left.=0.69\right)$ was similar to the theoretical line of perfect correlation $\left(\mathrm{R}^{2}=1\right.$, slope $=1$ ) (Fig.7). Three-dimensional stress maps demonstrated lower stresses for the RA-on compared to the AA-on configuration (Fig.8). Peak stresses were 7.7 $\mathrm{MPa}$ (RA-on) and 8.2 $\mathrm{MPa}$ (AA-on) at the locking screws.

\subsection{Discussion}

Overall there was reasonable agreement between experimental strain data obtained from mechanical tests and FE analysis, thereby validating the FE model. The resulting FE threedimensional stress maps may serve as preliminary estimates for this fracture repair method once healing begins, albeit at low axial loads. 
Compared to previous studies, the present study yielded favorable results despite some differences in methodology. Current axial stiffnesses were $682 \mathrm{~N} / \mathrm{mm}$ (RA-on) and 1152 $\mathrm{N} / \mathrm{mm}$ (AA-on) with compressive medial microstrain ranges of 294-968 (mechanical tests) and 363-799 (FEA). Kraemer et al. (1996) loaded intact human cadaveric femurs equipped with the Russell-Taylor nail (axial stiffness $=850 \mathrm{~N} / \mathrm{mm}$; microstrain $=975$ ) and a long intramedullary rod hip screw (axial stiffness $=750 \mathrm{~N} / \mathrm{mm}$; microstrain $=1125$ ).

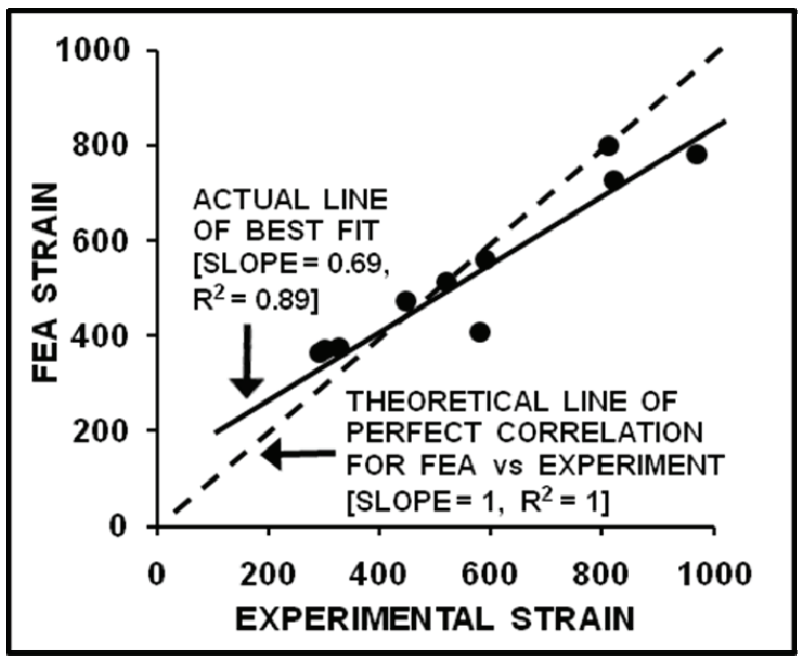

Fig. 7. Correlation of surface strain obtained from experiment and FEA. The actual line of best fit showed a high linear correlation, $\mathrm{R}^{2}$, but its slope was only moderately close to that of the theoretical line of perfect correlation. Values are in microstrain units $(\mu \mathrm{m} / \mathrm{mm})$.

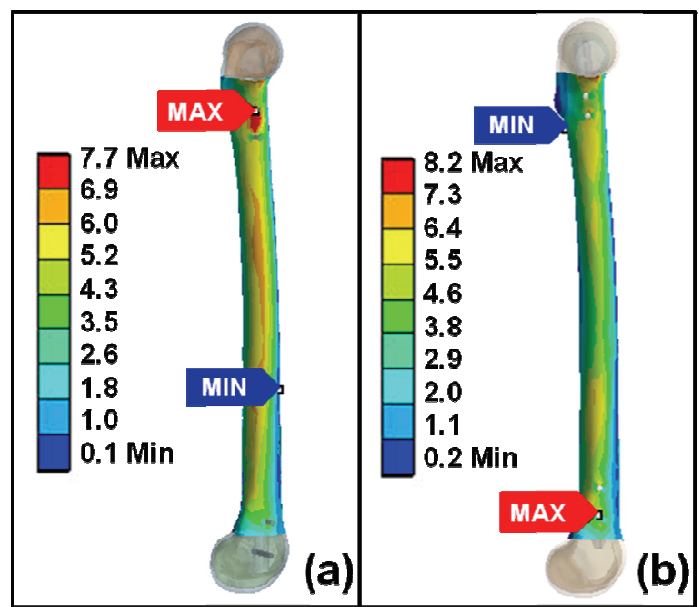

Fig. 8. FEA stress distributions. (a) RA-on configuration stress map. (b) AA-on configuration stress map. Stresses shown are equivalent Von Mises stresses (MPa). 
Cheung et al. (2004) tested the same synthetic femur used currently and instrumented it with a Synthes reamed retrograde intramedullary nail, yielding microstrains that ranged from approximately 800 (compressive) to 200 (tensile).

Clinically, the majority of axial load is taken by the femur in a femur-nail construct during walking gait. Cheung et al. (2004) showed that an intact femur instrumented with a fully locked intramedullary nail absorbs about 70 to $74 \%$ of total axial force during the stance phase and $91 \%$ during the swing phase of gait. Although load sharing was not monitored in the present investigation, similar proportions would be expected because the synthetic femurs used were identical to Cheung et al. and the axial forces applied were almost identical (600 N versus $580 \mathrm{~N}$ presently).

The T2 nail offers optimal configurations that may be useful for young healthy and older patients. A previous study using the same test setup showed that axial stiffness was $1290 \pm$ $30 \mathrm{~N} / \mathrm{mm}$ for these same synthetic femurs without nails, thereby modeling young healthy bone, and $757 \pm 264 \mathrm{~N} / \mathrm{mm}$ for human cadaveric femurs without nails with an average age of 75.4 years (Papini et al., 2007). By matching these intact femur stiffnesses with current data for the instrumented femurs, the AA-on configuration may be optimal for young healthy patient bones, whereas the RA-on arrangement may be more suitable for older patients. However, this suggestion would need to be demonstrated at higher clinical loads.

Stress maps showed higher peak stresses for AA-on compared to RA-on around locking screws. Screw locations could potentially be sites of clinical failure once weight bearing is permitted (Pankovich and Davenport, 2006). The relative similarity of stress distribution along the diaphysis of the two configurations suggests that neither would necessarily be more susceptible to failure at mid-shaft. However, the application of higher clinical forces would need to be performed experimentally to confirm this supposition.

The weaknesses of this study should be recognized. Firstly, low static axial loads were applied experimentally and modeled using FEA. The femur, in reality, is exposed to higher dynamic forces and moments during activities of daily living (Bergmann et al., 1993).

Secondly, the FE model assumed linear isotropic bone properties. In reality, nonlinearity, anisotropy, and viscoelasticity might affect bulk mechanical behavior of femurs. Even so, comparison of FEA, synthetic femurs, and human cadaveric femurs previously performed (Papini et al., 2007) suggests linear behavior is a good approximation.

Thirdly, synthetic, rather than human, femurs were used. However, these synthetic surrogates have been successfully used in investigations dealing with femoral middiaphyseal fracture repair constructs (Talbot et al., 2008a, 2008b; Zdero et al., 2008a). They have demonstrated good agreement in axial and torsional stiffness when compared to human cadaveric femurs (Heiner and Brown, 2001, 2003; Papini et al., 2007).

Fourthly, although experimental and FE strains showed reasonable agreement, a clockwise tilt of the actual line of best fit indicates exaggeration of experimental strains. Experimentally, this may have been due to femoral head movement medially under the flat load applicator plate, which would increase the strain values, whereas the FE model restricted femoral head movement to only the vertical axial direction.

Finally, load to failure, i.e. strength, was not currently assessed. This would be an important parameter to measure to fully understand the potential benefits and limitations of the T2 nail. Even so, the investigation was able to identify locations of high stress around locking screws, which could be potential sites of failure at clinical loads. 
In conclusion, the RA-on nail may be more suitable for the elderly, whereas the AA-on nail may be more optimal for the young. The results simulated post-operative stability at low static axial loads once fracture union begins to occur at the mid-shaft fracture site.

\section{Conclusion}

In orthopaedic biomechanics, an assessment of the mechanical properties of human bones and implants can be done using mechanical experimentation combined with FEA. A practical overview of the methodology was presently given. The outcome measures discussed were stiffness, strength, strain, and stress. A real-world case study was also examined. The authors hope that students, engineers, and clinicians will now be better prepared to engage in more effective orthopaedic biomechanics research.

\section{References}

Alho, A. (1996). Concurrent ipsilateral fractures of the hip and shaft of the femur: a metaanalysis of 659 cases. Acta Orthop Scand, Vol.67, No.1, 19-28.

Anderson, A.E., Ellis, B.J., and Weiss, J.A. (2007). Verification, validation and sensitivity studies in computational biomechanics. Comput Methods Biomech Biomed Engin. Vol.10, No.3, 171-84.

Baird, D.C. (1962). Experimentation: An Introduction to Measurement Theory and Experiment Design, Prentice-Hall, Englewood Cliffs, USA.

Bergmann, G., Graichen, F., and Rohlmann, A. (1993). Hip joint loading during walking and running measured in two patients. J Biomech, Vol.26, No.8, 969-990.

Bougherara, H., and Bureau, M.N. (2008). Biomimetic composite-metal hip resurfacing implant. Research Letters in Materials Science, June 8, No. 368985.

Bougherara, H., Bureau, M.N., Campbell, M., Vadean, A., and Yahia, L. (2007). Design of a biomimetic polymer-composite hip prosthesis. J Biomed Mater Res A, Vol. 82, No.1, 27-40.

Bougherara, H., Zdero, R., Miric, M., Shah, S., Hardisty, M., Zalzal, P., and Schemitsch, E.H. (2009). The biomechanics of the T2 femoral nailing system: a comparison of synthetic femurs with finite element analysis. Proc Instn Mech Engrs (Part H): J Engineering in Medicine, Vol.223, No.H3, 303-314.

Bougherara, H., Miric, M., Zdero, R., Shah, S., Hardisty, M., Zalzal, P., and Schemitsch, E.H. (2010a). A novel biomimetic intramedullary nailing implant for the treatment of femur fracture. International Journal of Engineering, in press.

Bougherara, H., Zdero, R., Mahboob, Z., Dubov, A., Suraj, S., and Schemitsch, E.H. (2010b). The biomechanics of a validated finite element model of stress shielding in a novel hybrid total knee replacement. Proc Instn Mech Engrs (Part H): J Engineering in Medicine, in press.

Bougherara, H., Bureau, M.N., and Yahia, L. (2010c). Bone remodeling in a new biomimetic polymer-composite hip stem. J Biomed Mat Res Part A, Vol.92, No.1, 164-174.

Bougherara, H., Klika, V., Maršík, F., Mařík, I.A., and Yahia, L. (2010d). New predictive model for monitoring bone remodeling. J Biomed Mater Res A, in press.

Brekelmans, W.A.M., Poort, H.W., and Sloof, T.J. (1972). A new method to analyse the mechanical behaviour of skeletal parts. Acta Orthop Scand, Vol.43, No.5, 301-317. 
Buchler, P., and Farron, A. (2004). Benefits of an anatomical reconstruction of the humeral head during shoulder arthroplasty: a finite element analysis. Clin Biomech (Bristol, Avon), Vol.19, No.1, 16-23.

Cheal, E.J., Hayes, W.C., White, A.A., III, and Perren, S.M. (1983). Stress analysis of a simplified compression plate fixation system for fractured bones. Comput Struct, Vol.17, No.5-6, 845-855.

Cheal, E.J., Hayes, W.C., White, A.A., III, and Perren, S.M. (1984). Three-dimensional finite element analysis of a simplified compression plate fixation system. J Biomech Eng, Vol.106, No.4, 295-301.

Cheal, E.J., Hayes, W.C., White, A.A., III, and Perren, S.M. (1985). Stress analysis of compression plate fixation and its effects on long bone remodelling. J Biomech, Vol.18, No.2, 141-150.

Cheung, G., Zalzal, P., Bhandari, M., Spelt, J.K., and Papini, M. (2004). Finite element analysis of a femoral retrograde intramedullary nail subject to gait loading. Med Eng Phys, Vol.26, No.2, 93-108.

Chong, A.C., Friis, E.A., Ballard, G.P., Czuwala, P.J., and Cooke, F.W. (2007). Fatigue performance of composite analogue femur constructs under high activity loading. Ann Biomed Eng, Vol.35, No.7, 1196-1205.

Claes, L.E., and Ito, K. (2005). Biomechanics of fracture fixation and fracture healing, In: Basic Orthopaedic Biomechanics and Mechano-Biology: Third Edition, V.C. Mow and R. Huiskes (Eds.), 563-584, Lippincott Williams and Wilkins, Philadelphia, USA.

Cristofolini, L., and Viceconti, M. (2000). Mechanical validation of whole bone composite tibia models. J Biomech, Vol.33, No.3, 279-288.

Cristofolini, L., Viceconti, M., Cappello, A., and Toni, A. (1996). Mechanical validation of whole bone composite femur models. J Biomech, Vol.29, No.4, 525-535.

Dammak, M., Shirazi-Adl, A., Schwartz, J., and Gustavson, L. (1997). Friction properties at the bone-metal interface: Comparison of four different porous metal surfaces. $J$ Biomed Mater Res, Vol. 35, No.3, 329-336.

Davis, E.T., Olsen, M., Zdero, R., Waddell, J.P., and Schemitsch, E.H. (2008). Femoral neck fracture following hip resurfacing: the effect of alignment of the femoral component. J Bone Joint Surg Br, Vol.90, No.11, 1522-1527.

Davis, E.T., Olsen, M., Zdero, R., Papini, M., Waddell, J.P., and Schemitsch, E.H. (2009). A biomechanical and finite element analysis of femoral neck notching during hip resurfacing. J Biomech Eng, Vol.131, No.4, 041002-1-8.

Dennis, M.G., Simon, J.A., Kummer, F.J., Koval, K.J., and Di Cesare, P.E. (2000). Fixation of periprosthetic femoral shaft fractures occurring at the tip of the stem: a biomechanical study of 5 techniques. J Arthroplasty, Vol.15, No.4, 523-528.

Dennis, M.G., Simon, J.A., Kummer, F.J., Koval, K.J., and Di Cesare, P.E. (2001). Fixation of periprosthetic femoral shaft fractures: a biomechanical comparison of two techniques. J Orthop Trauma, Vol.15, No.3, 177-80.

Duda, G.N., Heller, M., Albinger, J., Schulz, O., Schneider, E., and Claes, L. (1998). Influence of muscle forces on femoral strain distribution. J Biomech, Vol.31, No.9, 841-846.

Dunlap, J.T., Chong, A.C.M., Lucas, G.L., and Cooke, F.W. (2008). Structural properties of a novel design of composite analogue humeri models. Ann Biomed Eng, Vol.36, No.11, 1922-1926. 
Edmondston, S.J., Singer, K.P., Day, R.E., Breidahl, P.D., and Price, R.I. (1994). In-vitro relationships between vertebral body density, size, and compressive strength in the elderly thoracolumbar spine. Clin Biomech (Bristol, Avon), Vol.9, No.3, 180-186.

Elstrom, J.A., Virkus, W.W., and Pankovich, A.M. (Eds.) (2006). Handbook of Fractures: Third Edition, McGraw-Hill, New York, USA.

Forcione, A. and Shirazi-Adl A. (1990). Biomechanical analysis of a porous-surfaced knee implant: A finite element contact problem with nonlinear friction. In: Mechanical Engineering Forum, Canadian Society of Mechanical Engineers, University of Toronto, Toronto, Canada, Vol.2, 19-24.

Fulkerson, E., Koval, K., Preston, C.F., Iesaka, K., Kummer, F.J., and Egol, K.A. (2006). Fixation of periprosthetic femoral shaft fractures associated with cemented femoral stems: a biomechanical comparison of locked plating and conventional cable plates. J Orthop Trauma. Vol.20, No.2, 89-93.

Grant, J.A., Bishop, N.E., Götzen, N., Sprecher, C., Honl, M., and Morlock, M.M. (2007). Artificial composite bone as a model of human trabecular bone: The implant-bone interface. J Biomech, Vol.40, No.5, pp.1158-1164.

Heiner, A.D., and Brown, T.D. (2001). Structural properties of a new design of composite replicate femurs and tibias. J Biomech, Vol.34, No.6, 773-781.

Heiner, A.D., and Brown, T.D. (2003). Structural properties of an improved redesign of composite replicate femurs and tibias. Transactions 29th Society for Biomaterials, Vol.26, Reno, NV, USA, April 30-May 3, p.702.

Hernandez, C., Beaupré, G.S., and Carter, D.R. (2000). A model of mechanobiologic and metabolic influences on bone adaptation. J Rehabil Res Dev, Vol.37, No.2, 235- 244.

Holman, J. (2000). Experimental methods for engineers: Seventh edition, McGraw-Hill, New York, USA.

Huiskes, R. (1982). On the modeling of long bones in structural analyses. J Biomech, Vol.15, No.1, 65-69.

Huiskes, R., and Chao, E.Y. (1983). A survey of finite element analysis in orthopedic biomechanics: the first decade. J Biomech, Vol.16, No.6, 385-409.

Huiskes, R., and Stolk, J. (2005). Biomechanics and preclinical testing of artificial joints: the hip, In: Basic Orthopaedic Biomechanics and Mechano-Biology: Third Edition, V.C. Mow and R. Huiskes (Eds.), 585-656, Lippincott Williams and Wilkins, Philadelphia, USA.

Huiskes, R., and Van Rietbergen, B. (2005). Biomechanics of Bone, In: Basic Orthopaedic Biomechanics and Mechano-Biology: Third Edition, V.C. Mow and R. Huiskes (Eds.), 123-179, Lippincott Williams and Wilkins, Philadelphia, USA.

Huiskes, R., Weinans, H., Grootenboer, H.J., Dalstra, M., Fudala, B., Slooff, T.J. (1987). Adaptive bone-remodeling theory applied to prosthetic-design analysis. J Biomech, Vol.20, No.11-12, 1135-1150.

Huiskes, R., Ruimerman, R., Harry van Lenthe, G., and Janssen, J.D. (2000). Effects of mechanical forces on maintenance and adaptation of form in trabecular bone. Nature, Vol.405, No.6787, 704-706.

Iwamoto, M., Miki, K., Mohammad, M., Nayef, A., Yang, K.H., Begeman, P.C., and King, A.I. (2000). Development of a finite element model of the human shoulder. Stapp Car Crash J, Vol.44, 281-297. 
Kraemer, W.J., Hearn, T.C., Powell, J.N., and Mahomed, N. (1996). Fixation of segmental subtrochanteric fractures. A biomechanical study. Clin Orthop Relat Res, Vol.332, pp.71-79.

Le Huec, J.C., Lafage, V., Bonnet, X., Lavaste, F., Josse, L., Liu, M., and Skalli, W. (2010). Validated finite element analysis of the maverick total disc prosthesis. J Spinal Disord Tech, Jan 11. [Epub ahead of print]

Lescheid, J., Zdero, R., Shah, S., Kuzyk, P.R.T., and Schemitsch, E.H. (2010). The biomechanics of locked plating for repairing proximal humerus fractures with or without medial cortical support. J Trauma, Jan 28 [Epub ahead of print].

Lewis, G., Clark, M.C., Harber, M.S., and Vaughan, M. (1996). The elbow joint and its total arthroplasty. Part II. Finite element study. Biomed Mater Eng, Vol.6, No.5, 367-377.

Lochmüller, E.M., Krefting, N., Burklein, D., and Eckstein, F. (2001). Effect of fixation, softtissues, and scan projection on bone mineral measurements with dual x-ray absorptiometry (DXA). Calcif Tissue Int, Vol.68, No.3, 140-145.

Lotke, P.A., and Ecker M.L. (1977). Influence of positioning of prosthesis in total knee replacement. J Bone Joint Surg Am, Vol.59, No.1, 77-79.

Maldonado, Z.M., Seebeck, J., Heller, M.O., Brandt, D., Hepp, P., Lill, H., and Duda, G.N. (2003). Straining of the intact and fractured proximal humerus under physiologicallike loading. J Biomech, Vol.36, No.12, 1865-1873.

Martens, M., Van Audekercke, R., De Meester, P., and Mulier, J.C. (1980). The mechanical characteristics of the longbones of the lower extremity in torsional loading. $J$ Biomech, Vol.13, No.8, 667-676.

Martens, M., Van Audekercke, R., De Meester, P., and Mulier, J.C. (1986). Mechanical behaviour of femoral bones in bending loading. J Biomech, Vol.19, No.6, 443-454.

Mather, B.S. (1968). Observations on the effects of static and impact loading on the human femur. J Biomech, Vol.1, No.4, 331-335.

McConnell, A., Zdero, R., Syed, K., Peskun, C., and Schemitsch, E.H. (2008). The biomechanics of ipsilateral intertrochanteric and femoral shaft fractures: a comparison of 5 fracture fixation techniques. J Orthop Trauma, Vol.22, No.8, 517-524.

McElhaney, J., Fogle, J., Byers, E., and Weaver, G. (1964). Effect of embalming on the mechanical properties of beef bone. J Appl Physiology, Vol.19, Nov, 1234-1236.

Oh, J.K., Sahu, D., Ahn, Y.H., Lee, S.J., Tsutsumi, S., Hwang, J.H., Jung, D.Y., Perren, S.M., and Oh, C.W. (2010). Effect of fracture gap on stability of compression plate fixation: a finite element study. J Orthop Res, Vol.28, No.4, 462-467.

Orr, T.E., and Carter, D.R. (1985). Stress analyses of joint arthroplasty in the proximal humerus. J Orthop Res, Vol.3, No.3, 360-371.

OTA (1996). Orthopaedic Trauma Association Committee for Coding and Classification. Fracture and dislocation compendium. J Orthop Trauma. Vol.10, Supp.1, 51-55.

Panagiotopoulou, O. (2009). Finite element analysis (FEA): applying an engineering method to functional morphology in anthropology and human biology. Ann Hum Biol, Vol.36, No.5, 609-623.

Pankovich, A.M., and Davenport, A.M. (2006). Fractures of the femoral shaft, In: Handbook of Fractures, 3rd Edition, J.A. Elstrom, W.W. Virkus, and A.M. Pankovich (Eds.), 293303, McGraw-Hill, Toronto, Canada. 
Papini, M., Zdero, R., Schemitsch, E.H., and Zalzal, P. (2007). The biomechanics of human femurs in axial and torsional loading: comparison of finite element analysis, human cadaveric femurs, and synthetic femurs. J Biomech Eng, Vol.129, No.1, 12-19.

Perren, S.M. (1975). Physical and biological aspects of fracture healing with special reference to internal fixation. Clin Orthop Rel Res. Vol.138, 175-194.

Roesler, H. (1987). The history of some fundamental concepts in bone biomechanics. J Biomech, Vol.20, No.11-12, 1025-1034.

Rouhi, G., Epstein, M., Sudak, L., and Herzog, W. (2007). Modeling bone resorption using mixture theory with chemical reactions, J Mech Mater Struct, Vol.2, No.6, 1141-1155.

Sakai, K., Kiriyama, Y., Kimura, H., Nakamichi, N., Nakamura, T., Ikegami, H., Matsumoto, H., Toyama, Y., and Nagura, T. (2010). Computer simulation of humeral shaft fracture in throwing. J Shoulder Elbow Surg, Vol.19, No.1, 86-90.

Schemitsch, E.H., Bhandari, M., Boden, S., Bourne, R., Bozic, K.J., Jacobs, J., and Zdero, R. (2010). The evidence-based approach in bringing new orthopaedic devices to market. J Bone Joint Surg Am, Vol.92, No.4, 1030-1037.

Schipplein, O.D., and Andriacchi, T.P. (1991). Interaction between active and passive knee stabilizers during level walking. J Orthop Res, Vol.9, No.1, 113-119.

Schonning, A., Oommen, B., Ionescu, I., and Conway, T. (2009). Hexahedral mesh development of free-formed geometry: The human femur exemplified. ComputerAided Design, Vol.41, No.8, 566-572.

Schutte, S., van den Bedem, S.P.W., van Keulen, F., van der Helm, F.C.T, and Simonsz, H.J. (2006). A finite-element analysis model of orbital biomechanics. Vision Research, Vol. 46, No.11, 1724-1731.

Schneider, E., Michel, M.C., Genge, M., and Perren, S.M. (1990). Loads acting on an intramedullary femoral nail, In: Bergmann, G., Graichen, F., Rohlmann, A., eds, Implantable Telemetry in Orthopaedics, Berlin: Freie Universitat Berlin, pp.221-227.

Schneider, E., Michel, M.C., Genge, M., Zuber, K., Ganz, R., and Perren, S.M. (2001). Loads acting in an intramedullary nail during fracture healing in the human femur. $J$ Biomech, Vol.34, No.7, 849-857.

Shimmin, A.J., Walter, W.L., and Esposito, C. (2010). The influence of the size of the component on the outcome of resurfacing arthroplasty of the hip: a review of the literature. J Bone Joint Surg Br, Vol.92, No.4, 469-76.

Simões, J.A., and Marques, A.T. (2005). Design of a composite hip femoral prosthesis. Materials and Design, Vol.26, No.5, 391-401.

Talbot, M., Zdero, R., and Schemitsch, E.H. (2008a). Cyclic loading of periprosthetic fracture fixation constructs. J Trauma, Vol.64, No.5, 1308-1312.

Talbot, M., Zdero, R., Garneau, D., Cole, P.A., and Schemitsch, E.H. (2008b). Fixation of longbone segmental defects: a biomechanical study. Injury, Vol.39, No.2, 181-186.

Taylor, M., Tanner, K.E., Freeman, M.A.R., and Yettram, A.L. (1995). Cancellous bone stresses surrounding the femoral component of a hip prosthesis: an elastic-plastic finite element analysis, Med Eng Phys, Vol.17, No.7, 544-550.

Taylor, M.E., Tanner, K.E., Freeman, M.A.R., and Yettram, A.L. (1996). Stress and strain distribution within the intact femur: compression or bending? Med Eng Phys, Vol.18, No.2, 122-131. 
Taylor, M., Verdonschot, N., Huiskes, R., and Zioupos, P. (1999). A combined finite element method and continuum damage mechanics approach to simulate the in vitro fatigue behavior of human cortical bone. J Mater Sci: Mater Med, Vol.10, No.12, 841846.

van Rietbergen, B., Weinans, H., Huiskes, R., and Odgaard, O. (1995). A new method to determine the trabecular bone elastic properties and loading using micromechanical finite element models. J Biomech, Vol.28, No.1, 69-81.

Wainer, R.A., Wright, P.H., Gilbert, J.A., and Taylor, D.F. (1990). Biomechanics of ender rods, compression screw, and Zickel nail in the fixation of stable subtrochanteric femur osteotomies. J Orthop Trauma, Vol.4, No.1, 58-63.

Wang, C.J., Yettram, A.L., Yao, M.S., and Proctor, P. (1998). Finite element analysis of a gamma nail within a fractured femur. Med Eng Phys, Vol.20, No.9, 677-683.

Weinans, H., Huiskes, R., Van Rietbergen, B., Sumner, D.R., Turner, T.M., and Galante, J.O. (1993). Adaptive bone remodeling around bonded noncemented total hip arthroplasty: A comparison between animal experiments and computer simulation. J Orthop Res, Vol. 11, No.4, 500-513.

Zdero, R., Walker, R., Waddell, J.P., and Schemitsch, E.H. (2008a). Biomechanical evaluation of periprosthetic femoral fracture fixation. J Bone Joint Surg Am, Vol.90, No.5, 10681077.

Zdero, R., Olsen, M., Bougherara, H., and Schemitsch, E.H. (2008b). Cancellous bone screw purchase: a comparison of synthetic femurs, human femurs, and finite element analysis. Proc Instn Mech Engrs (Part H): J Engineering in Medicine, Vol.222, No.H8, 1175-1183.

Zdero, R., Elfallah, K., Olsen, M., and Schemitsch, E.H. (2009a). Cortical screw purchase in synthetic and human femurs. J Biomech Eng, Vol.131, No.9, 094503-1-7.

Zdero, R., Olsen, M., Elfatori, S., Skrinskas, T., Nourhosseini, H., Whyne, C., Schemitsch, E.H., and Von Schroeder, H. (2009b). Linear and torsional mechanical characteristics of intact and reconstructed scapholunate ligaments. J Biomech Eng, Vol.131, No.4, 041009-1-7.

Zdero, R., Bougherara, H., Dubov, A., Shah, S., Zalzal, P., Mahfud, A., and Schemitsch, E.H. (2010a). The effect of cortex thickness on intact femur biomechanics: a comparison of finite element analysis with synthetic femurs. Proc Instn Mech Engrs (Part H): J Engineering in Medicine, in press.

Zdero, R., Shah, S., Mosli, M., and Schemitsch, E.H. (2010b). The effect of load application rate on the biomechanics of synthetic femurs. Proc Instn Mech Engrs (Part H): J Engineering in Medicine, Vol.224, No.H4, 599-605. 


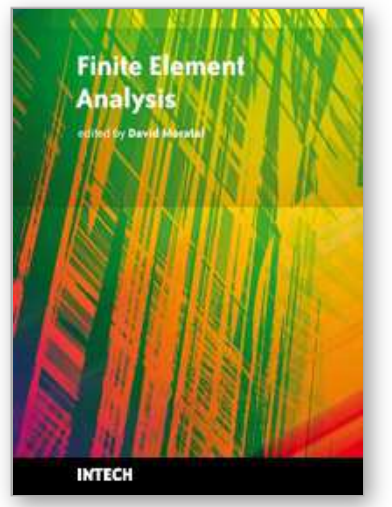

\author{
Finite Element Analysis \\ Edited by David Moratal
}

ISBN 978-953-307-123-7

Hard cover, 688 pages

Publisher Sciyo

Published online 17, August, 2010

Published in print edition August, 2010

Finite element analysis is an engineering method for the numerical analysis of complex structures. This book provides a bird's eye view on this very broad matter through 27 original and innovative research studies exhibiting various investigation directions. Through its chapters the reader will have access to works related to Biomedical Engineering, Materials Engineering, Process Analysis and Civil Engineering. The text is addressed not only to researchers, but also to professional engineers, engineering lecturers and students seeking to gain a better understanding of where Finite Element Analysis stands today.

\title{
How to reference
}

In order to correctly reference this scholarly work, feel free to copy and paste the following:

Rad Zdero and Habiba Bougherara (2010). Orthopaedic Biomechanics: A Practical Approach to Combining Mechanical Testing and Finite Element Analysis, Finite Element Analysis, David Moratal (Ed.), ISBN: 978-953307-123-7, InTech, Available from: http://www.intechopen.com/books/finite-element-analysis/orthopaedicbiomechanics-a-practical-approach-to-combining-mechanical-testing-and-finite-element-ana

\section{INTECH}

open science | open minds

\section{InTech Europe}

University Campus STeP Ri

Slavka Krautzeka 83/A

51000 Rijeka, Croatia

Phone: +385 (51) 770447

Fax: +385 (51) 686166

www.intechopen.com

\section{InTech China}

Unit 405, Office Block, Hotel Equatorial Shanghai

No.65, Yan An Road (West), Shanghai, 200040, China

中国上海市延安西路65号上海国际贵都大饭店办公楼 405 单元

Phone: +86-21-62489820

Fax: +86-21-62489821 
(C) 2010 The Author(s). Licensee IntechOpen. This chapter is distributed under the terms of the Creative Commons Attribution-NonCommercialShareAlike-3.0 License, which permits use, distribution and reproduction for non-commercial purposes, provided the original is properly cited and derivative works building on this content are distributed under the same license. 